\title{
Part I: The Role of Maintenance Therapy in Patients With Multiple Myeloma Undergoing Autologous Hematopoietic Stem Cell Transplantation
}

Philip L. McCarthy, MD

\begin{abstract}
Multiple myeloma remains a highly treatable but incurable disease. New agents with improved efficacy have increased the response to induction treatment. These agents have been adapted for use in maintenance therapy strategies to improve responses and delay relapse/progression with the ultimate goal of improved overall survival. Recent trials have shown that the immunomodulatory drugs thalidomide and lenalidomide; the proteasome inhibitor bortezomib; and the bisphosphonate zoledronate improve time to progression and overall survival. Introduction of new therapies, alone or in combination with existing agents, may lead to increased improvement and prolongation of disease control after autologous hematopoietic stem cell transplantation for transplant-eligible patients. (JNCCN 2013;11:35-42)
\end{abstract}

Multiple myeloma (MM) is an incurable disease. One major goal in the treatment of patients with MM is to improve progression-free and overall survival (PFS and OS, respectively). In the past 10 years, the median OS for patients with MM has increased. ${ }^{1}$ This improved OS is likely from the use of novel agents that improve PFS, including the immunomodulatory drugs (IMiDs) thalidomide ${ }^{2,3}$ and lenalidomide, ${ }^{4-7}$ and the proteasome inhibitor bortezomib. ${ }^{8-13}$ These drugs, usually as part of

From the Blood and Marrow Transplant Program, Roswell Park Cancer Institute, Buffalo, New York.

Submitted July 24, 2012; accepted for publication

December 14, 2012.

Dr. McCarthy has disclosed that he served on the advisory board for for Celgene Corporation and Janssen.

Correspondence: Philip L. McCarthy, MD, Blood and Marrow

Transplant Program, Roswell Park Cancer Institute, Elm and Carlton

Streets, Buffalo, NY 14263. E-mail: philip.mccarthy@roswellpark.org combination regimens, have made a major impact on time to progression (TTP), PFS, and OS. Attaining and maintaining response have been important goals in the management of MM after autologous hematopoietic stem cell transplant (AHSCT). ${ }^{1,14}$ Researchers have postulated that depth of response is important in maintaining this response ${ }^{15-18}$; however, patients attaining very good partial responses have similar outcomes to those experiencing complete responses. ${ }^{19}$ Target areas for improvement in the MM treatment continuum for transplant-eligible patients include induction, $\mathrm{AH}$ SCT dose-intensive therapy, consolidation, and maintenance. This article focuses on the role of maintenance therapy after AHSCT.

An optimal agent for maintaining response should be effective, well-tolerated with manageable toxicities, simple to administer, and feasible for long-term administration. Older agents, including lower doses of melphalan, interferon- $\alpha$, and glucocorticoids, have been used for maintenance after primary induction therapy. ${ }^{20-23}$ Their long-term use was limited by toxicity and modest efficacy, and because these agents, except for interferon- $\alpha$ and glucocorticoids, have not been studied in the AHSCT setting. Other treatments have been used to try to improve efficacy and determine suitability for long-term use.

\section{Thalidomide}

Thalidomide has been extensively studied in large phase III studies as a single agent or in combination with glucocorticoids. Of 5 large phase III studies, 3 showed an 


\section{McCarthy}

increase in OS in the thalidomide $\operatorname{arm}^{24-28}$ (Table 1). Three studies of maintenance therapy involving thalidomide plus glucocorticoids did not show an OS benefit. ${ }^{29-31}$ Thalidomide maintenance seems to benefit patients with standard risk and not who do not have a deletion of chromosome 13 chromosome. ${ }^{24}$ Two recent studies ${ }^{27,28}$ did not show an OS benefit, the latest ${ }^{28}$ being a study of 1970 patients that randomized 820 who underwent transplantation to either thalidomide maintenance therapy or no maintenance. However, in patients receiving Total Therapy 2, thalidomide improved outcomes of those with cytogenetic abnormalities, but postrelapse survival was decreased compared with those not receiving thalidomide. ${ }^{32}$ Long-term thalidomide therapy may cause neuropathy, resulting in up to a $60 \%$ discontinuation rate because of toxicity. Therefore, other agents have been considered for maintenance therapy.

\section{Lenalidomide}

Lenalidomide has been shown to be effective for salvage and induction therapy. ${ }^{4,5}$ It is considered a feasible maintenance treatment because it is an oral agent, has efficacy in low doses, and, as a single agent, can be given orally and has a well-defined toxicity profile. $^{32}$ The major toxicities of lenalidomide at the initiation of the maintenance studies were pri- marily hematologic, especially neutropenia and, to a lesser extent, thrombocytopenia and anemia. ${ }^{4-7,33}$ The role of maintenance therapy following induction therapy without AHSCT is discussed in detail in Part II by Palumbo and Mina elsewhere in issue, including a phase III study that examined the role of lenalidomide as maintenance therapy following induction and non-AHSCT therapy. ${ }^{34}$ This Part I describes the 2 phase III studies examining the role of lenalidomide maintenance therapy versus placebo after AHSCT in patients with newly diagnosed MM. ${ }^{35,36}$ Patients in both studies underwent induction therapy followed by AHSCT. All patients in the CALGB 100104 trial received a single AHSCT, and $79 \%$ of the patients in the Intergroupe Francophone du Myélome (IFM) 05-02 trial received a single AHSCT and 21\% received a tandem $\mathrm{AH}$ SCT. Patients in CALGB 100104 were randomized to either lenalidomide or placebo at approximately 100 days after AHSCT without consolidation. All patients in IFM 05-02 received 2 months of consolidation with lenalidomide within 100 days of AHSCT, followed by randomization to either lenalidomide or placebo. A significant improvement in TTP was seen for patients in the lenalidomide arm compared with those in the placebo arm in both CALGB 100104 (46 vs. 27 months; $P<.0001$ ) and IFM 05-02 (41 vs. 23 months; $P<.0001$; Table

\section{Table 1 Thalidomide Maintenance After Autologous Hematopoietic Stem Cell Transplant}

\begin{tabular}{|c|c|c|c|c|}
\hline & \multirow[b]{2}{*}{$\mathbf{N}$} & \multirow[b]{2}{*}{ Initial Dose (mg) } & \multicolumn{2}{|c|}{ Maintenance Versus No Maintenance } \\
\hline & & & EFS/PFS & OS \\
\hline Attal et al. ${ }^{24}$ & 597 & 400 & $\begin{array}{l}3-y \text { EFS } \\
52 \% \text { vs. } 37 \%(P<.009)\end{array}$ & $\begin{array}{l}4-y \text { OS } \\
87 \% \text { vs. } 75 \%(P<.04)\end{array}$ \\
\hline Barlogie et al. ${ }^{25}$ & 668 & 400 & $\begin{array}{l}5-y \text { EFS } \\
64 \% \text { vs. } 43 \%(P<.001)\end{array}$ & $\begin{array}{l}8-y \text { OS } \\
57 \% \text { vs. } 44 \%(P<.09)\end{array}$ \\
\hline Spencer et al. $26, a$ & 243 & 200 & $\begin{array}{l}3-y \text { PFS } \\
42 \% \text { vs. } 23 \%(P<.001)\end{array}$ & $\begin{array}{l}3-y \text { OS } \\
86 \% \text { vs. } 75 \%(P<.004)\end{array}$ \\
\hline Lokhorst et al. ${ }^{27}$ & 556 & 50 & $\begin{array}{l}\text { Median EFS } \\
43 \text { vs. } 22 \mathrm{mo}(P<.001)\end{array}$ & $\begin{array}{l}\text { Median OS } \\
73 \text { vs. } 60 \text { mo }(P<.77)\end{array}$ \\
\hline Morgan et al. ${ }^{28}$ & $\begin{array}{l}1970 \\
(820)^{b}\end{array}$ & 50 & $\begin{array}{l}\text { Median PFS (HSCT) } \\
30 \text { vs. } 23 \text { mo }(P<.003)\end{array}$ & $\begin{array}{l}3 \text { year OS } \\
75 \% \text { vs. } 80 \%(P<.26)\end{array}$ \\
\hline
\end{tabular}

Abbreviations: EFS, event-free survival; HSCT, hematopoietic stem cell transplant; OS, overall survival; PFS, progression-free survival.

${ }^{a}$ The Australian trial compared prednisolone versus prednisolone plus thalidomide maintenance therapy.

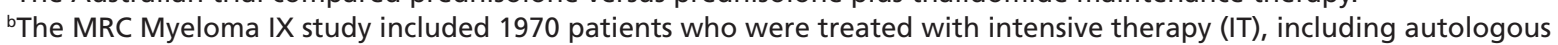
hematopoietic stem cell transplant (AHSCT; $n=1144$ ) or nonintensive therapy (NIT; $n=856)$. After induction therapy and completion of AHSCT in the IT arm, 820 IT and NIT patients were randomized to thalidomide $(n=408)$ or no thalidomide $(n=410)$. Of the thalidomide maintenance arm, 245 patients received IT and 163 received NIT. For the no-maintenance arm, 247 patients received IT and 163 received NIT. 
2). No difference was seen in OS in the IFM 05-02 study ( $73 \%$ vs. $75 \%$ ), whereas a significant difference in OS was seen between the lenalidomide and placebo arms in the CALGB 100104 study (85\% vs. $77 \% ; P=.028)$. An increased incidence of hematologic toxicity (neutropenia and, to a lesser extent, thrombocytopenia) and second primary malignancies (SPMs; Table 3) occurred in the lenalidomide arm of both studies. An event-free survival (EFS) analysis that included disease progressions, deaths, and SPMs (excluding nonmelanoma skin cancers) as events showed a superior EFS for the lenalidomide arms in both studies (Table 2). For the CALGB 100104 study, the cumulative incidence risk of SPM is greater for the lenalidomide arm compared with the placebo arm $(P<.008)$. The cumulative incidence risk of progressive disease $(P<.001)$ or death $(P<.002)$ is greater for the placebo arm compared with the lenalidomide arm. For the IFM 0502 study, the incidence of SPM was significantly related to study-group assignment, age, gender, and International Scoring System stage. Analyses are underway to more specifically determine risk factors for the development of second cancers.
Interest has been shown in the difference in the OS analyses of the 2 studies. Table 3 outlines some of the differences between the studies. Most (96\%) of the patients on the IFM 05-02 study received vincristine, doxorubicin, and dexamethasone (VAD) or bortezomib and dexamethasone (VD). For CALGB $100104,74 \%$ of patients received a regimen containing an $\mathrm{IMiD}$ and $41 \%$ a regimen containing bortezomib. A subset analysis was conducted of patients in CALGB 100104 receiving lenalidomide as part of induction treatment. For those receiving lenalidomide maintenance, 5 of 84 (6\%; hazard ratio [HR], 1.40; 95\% CI, 0.43-2.4) died compared with 19 of 82 (23\%; HR, 0.18; 95\% CI, -0.32-0.67) in the placebo arm $(P=.028)$. This finding suggests that continued lenalidomide exposure may improve OS in those experiencing response to induction therapy. To be eligible for the CALGB 100104 study, patients could not experience progression during induction therapy, and those progressing during induction were not eligible for study. Notably, approximately $8 \%$ of patients did not experience response to lenalidomide plus dexamethasone in the ECOG study. ${ }^{5}$ Whether the addition of agents such as bortezomib would im-

\begin{tabular}{|c|c|c|c|c|}
\hline & \multirow[b]{2}{*}{$\mathbf{N}$} & \multirow[b]{2}{*}{ Initial Dose } & \multicolumn{2}{|c|}{ Maintenance Versus No Maintenance } \\
\hline & & & TTP, PFS, or EFS & OS \\
\hline \multirow[t]{4}{*}{ CALGB $100104^{35, b}$} & 462 & $10 \mathrm{mg}(\mathrm{L})$ & $\begin{array}{l}\text { TTP } \\
46 \text { vs. } 27 \mathrm{mo}(P<.001)\end{array}$ & $\begin{array}{l}\text { Median follow-up of } 34 \text { mo } \\
85 \% \text { vs. } 77 \%(P=.028)\end{array}$ \\
\hline & & & $\begin{array}{l}\text { 3-y PFS rate } \\
66 \%(95 \% \mathrm{Cl}, 59-73)\end{array}$ & $\begin{array}{l}\text { 3-y OS rate } \\
88 \%(95 \% \mathrm{Cl}, 84-93)\end{array}$ \\
\hline & & & $\begin{array}{l}\text { vs. } \\
39 \%(95 \% \mathrm{Cl}, 33-48)\end{array}$ & $\begin{array}{l}\text { vs. } \\
80 \%(95 \% \mathrm{Cl}, 74-86)\end{array}$ \\
\hline & & & $\begin{array}{l}\text { EFS } \\
43 \text { vs. } 27 \mathrm{mo}(P<.001)\end{array}$ & \\
\hline \multirow[t]{3}{*}{ IFM $05-02^{36}$} & 605 & $10 \mathrm{mg}(\mathrm{L})$ & $\begin{array}{l}\text { PFS } \\
41 \text { vs. } 23 \mathrm{mo}(P<.001)\end{array}$ & $\begin{array}{l}\text { Median follow-up of } 45 \mathrm{mo} \\
74 \% \text { vs. } 76 \%(P=.7)\end{array}$ \\
\hline & & & $\begin{array}{l}4-y \text { PFS } \\
43 \% \text { vs. } 22 \%(P<.001)\end{array}$ & $\begin{array}{l}4-y \text { OS } \\
73 \% \text { vs. } 75 \%\end{array}$ \\
\hline & & & $\begin{array}{l}\text { EFS } \\
40 \text { vs. } 23 \text { mo }(P<.001)\end{array}$ & \\
\hline
\end{tabular}

\footnotetext{
Abbreviations: EFS, event-free survival; L, lenalidomide; OS, overall survival; PFS, progression-free survival; TTP, time to progression.

ancludes deaths, progressions, and second cancers.

${ }^{\mathrm{b}}$ The patients in CALGB 100104 receiving placebo were able to crossover to lenalidomide (86 of 128) after study unblinding in December 2009, whereas the patients in IFM 05-02 receiving placebo did not crossover to lenalidomide after study unblinding in January 2010. All patients in the IFM 05-02 lenalidomide arm stopped treatment as of January 2011. CALGB 100104 patient accrual occurred from April 2005 until July 2009. The range of time of exposure to lenalidomide is approximately 30 to 72 months. IFM 05-02 patient accrual occurred from July 2006 through August 2008. The range of time for exposure to lenalidomide is 32 to 59 months.
} 


\begin{tabular}{|c|c|c|c|c|}
\hline & \multicolumn{2}{|l|}{ CALGB 100104} & \multicolumn{2}{|l|}{ IFM 05-02 } \\
\hline Induction & \multicolumn{2}{|c|}{$\begin{array}{l}\text { Thalidomide- and lenalidomide- } \\
\text { containing regimens }(74 \%)\end{array}$} & \multicolumn{2}{|c|}{ VAD $(\approx 52 \%)$ and VD $(\approx 44 \%)$} \\
\hline Pre-AHSCT consolidation & \multicolumn{2}{|l|}{ None } & \multicolumn{2}{|l|}{ DCEP $(\approx 25 \%)$} \\
\hline Number of AHSCT & \multicolumn{2}{|l|}{1} & \multicolumn{2}{|c|}{$1(79 \%), 2(21 \%)$} \\
\hline Post-AHSCT consolidation & \multicolumn{2}{|l|}{ None } & \multicolumn{2}{|c|}{$\begin{array}{l}\text { Lenalidomide at } 25 \mathrm{mg} \text { daily for } 3 \text { of } 4 \\
\text { wk for } 2 \text { cycles within } 3 \text { mo post AHSCT } \\
\text { before randomization }\end{array}$} \\
\hline Median follow-up at unblinding & \multicolumn{2}{|l|}{$\approx 18 \mathrm{mo}$} & \multicolumn{2}{|c|}{$\approx 33 \mathrm{mo}$} \\
\hline $\begin{array}{l}\text { Median follow-up from } \\
\text { randomization }\end{array}$ & \multicolumn{2}{|l|}{$31 \mathrm{mo}$} & \multicolumn{2}{|l|}{$45 \mathrm{mo}$} \\
\hline Dosing schedule & \multicolumn{2}{|c|}{ 5-15 mg, starting dose $10 \mathrm{mg}$} & \multicolumn{2}{|c|}{5 to $15 \mathrm{mg}$, starting dose $10 \mathrm{mg}$} \\
\hline Time from first patient enrolled & \multicolumn{2}{|l|}{$78 \mathrm{mo}$} & \multicolumn{2}{|l|}{$62 \mathrm{mo}$} \\
\hline $\begin{array}{l}\text { Crossover at unblinding by placebo } \\
\text { patients to lenalidomide }\end{array}$ & \multicolumn{2}{|c|}{ Yes (86 of 128 eligible patients) } & \multicolumn{2}{|l|}{ No } \\
\hline Second primary malignancies & \multicolumn{2}{|c|}{$\approx 3$-fold increase } & \multicolumn{2}{|c|}{$\approx 2.6$-fold increase } \\
\hline Increase in AML/MDS & \multicolumn{2}{|l|}{ Yes } & \multicolumn{2}{|l|}{ No } \\
\hline Increase in ALL/HL & \multicolumn{2}{|l|}{ No } & \multicolumn{2}{|l|}{ Yes } \\
\hline Maintenance stopped & \multicolumn{2}{|l|}{ No } & \multicolumn{2}{|c|}{$\begin{array}{l}\text { Yes at a median of } \approx 32 \text { mo after } 2 \text { mo } \\
\text { consolidation }\end{array}$} \\
\hline Second Primary Malignancies & Lenalidomide & Placebo & Lenalidomide & Placebo \\
\hline ALL & 1 & 0 & 3 & 0 \\
\hline AML/MDS & 6 & 0 & 5 & 4 \\
\hline $\mathrm{HL}$ & 1 & 0 & 4 & 0 \\
\hline $\mathrm{NHL}$ & 0 & 1 & 1 & 1 \\
\hline Total hematologic malignancies & $8 / 231(3.5 \%)$ & $1 / 229(0.4 \%)$ & $13 / 306(4.2 \%)$ & $4 / 302(1.3 \%)$ \\
\hline Solid tumors & $10 / 231(4.3 \%)$ & $5 / 229(2.1 \%)$ & $10 / 306(3.3 \%)$ & $4 / 302(1.3 \%)$ \\
\hline Nonmelanoma skin cancers & $4 / 231(1.7 \%)$ & $3 / 229(1.3 \%)$ & $5 / 306(1.6 \%)$ & $3 / 302(1 \%)$ \\
\hline
\end{tabular}

Abbreviations: AHSCT, autologous hematopoietic stem cell transplant; ALL, acute lymphoblastic leukemia; AML/MDS, acute myeloid leukemia/myelodysplastic syndromes; DCEP dexamethasone, cyclophosphamide, etoposide, and cis-platinum; HL, Hodgkin lymphoma; NHL, non-Hodgkin lymphoma; VAD, vincristine, doxorubicin, and dexamethasone, VD, bortezomib and dexamethasone.

prove response and whether patients who experience poor response to lenalidomide-containing inductions would benefit from lenalidomide maintenance after AHSCT remains to be determined. The CALGB study allowed crossover from placebo to lenalidomide therapy after the primary end point (TTP) had been met in December 2009. Despite the crossover from placebo to lenalidomide, the OS benefit for lenalidomide persists as of the October 2011 analysis. This OS difference would be expected to diminish over time, because nearly all patients on-study experiencing no progression are now receiving lenalidomide. $\mathrm{Pa}$ tients on the lenalidomide arm of IFM 05-02 are no longer receiving lenalidomide because it was stopped at approxi- mately a median of 32 months due to concerns regarding SPM. Furthermore, whether an OS benefit will occur later in the IFM 05-02 study or whether continued lenalidomide maintenance therapy is necessary to see an OS difference remains to be determined.

\section{Bortezomib}

Bortezomib is another attractive agent for long-term maintenance, because it has shown efficacy in salvage and induction therapy. ${ }^{8-13}$ Bortezomib is also considered a promising maintenance treatment because it has efficacy in lower doses as a single agent and has 
a well-defined toxicity profile, predominantly peripheral neuropathy. The maintenance dosing was twice a month instead of 4 times over 2 weeks, thus it was expected to cause less peripheral neuropathy. The dosing was intravenous and not subcutaneous, the latter of which is associated with less neuropathy; whether subcutaneous dosing would have had the same effect during maintenance is not known. ${ }^{37}$ The recently published HOVON-65/GMMG-HD4 study showed superior PFS and OS when comparing bortezomib, doxorubicin, and dexamethasone (PAD) followed by bortezomib maintenance for 2 years versus $\mathrm{VAD}$ followed by thalidomide maintenance for 2 years $^{38}$ (Table 4). At a median followup of 41 months, the median PFS for the PAD arm was 35 months versus 28 months for the VAD arm $(P=.002)$. Using a multivariate analysis, the HR for PAD was 0.77 (95\% CI, 0.60-1.00; $P=.049)$. Selected high-risk patients with suitable donors went on to allogeneic HSCT, and patients treated in Germany received 2 transplants on this study. The patients receiving a double AHSCT seemed to have a superior OS (HR, 0.75; 95\% CI, 0.57-0.97; P=.03). Patients with poor-risk cytogenetic MM benefited from bortezomib maintenance therapy, particularly those with del(17p13) and $t(4 ; 14)$ abnormalities. ${ }^{38,39}$ The induction and maintenance portions of the PAD arm both contained bortezomib, whereas the VAD arm contained no bortezomib in either induction or maintenance. Therefore, whether the presence of bortezomib in induction or maintenance had the greatest effect on PFS and OS cannot be conclusively stated.

No difference in the incidence of SPM in the 2 study arms was seen in the HOVON65/GMMGHD4 trial; thus, bortezomib may not be associated with the development of SPM.

\section{Zoledronate}

The MRC Myeloma IX study examined different approaches to the treatment of patients with transplanteligible (intensive treatment [IT]) and transplant-ineligible (nonintensive treatment [NIT]) MM.40 One of the study questions asked whether intravenous versus oral bisphosphonates would have different effects on the incidence of skeletal-related events, so this form of therapy would not be considered maintenance therapy but more supportive care. All patients were randomized to intravenous zoledronate versus oral clodronate. Although the PFS for the IT arm was not different between the 2 bisphosphonate arms ( 25 vs. 25

\section{Table 4 Bortezomib and Zoledronate Maintenance After Autotransplant}

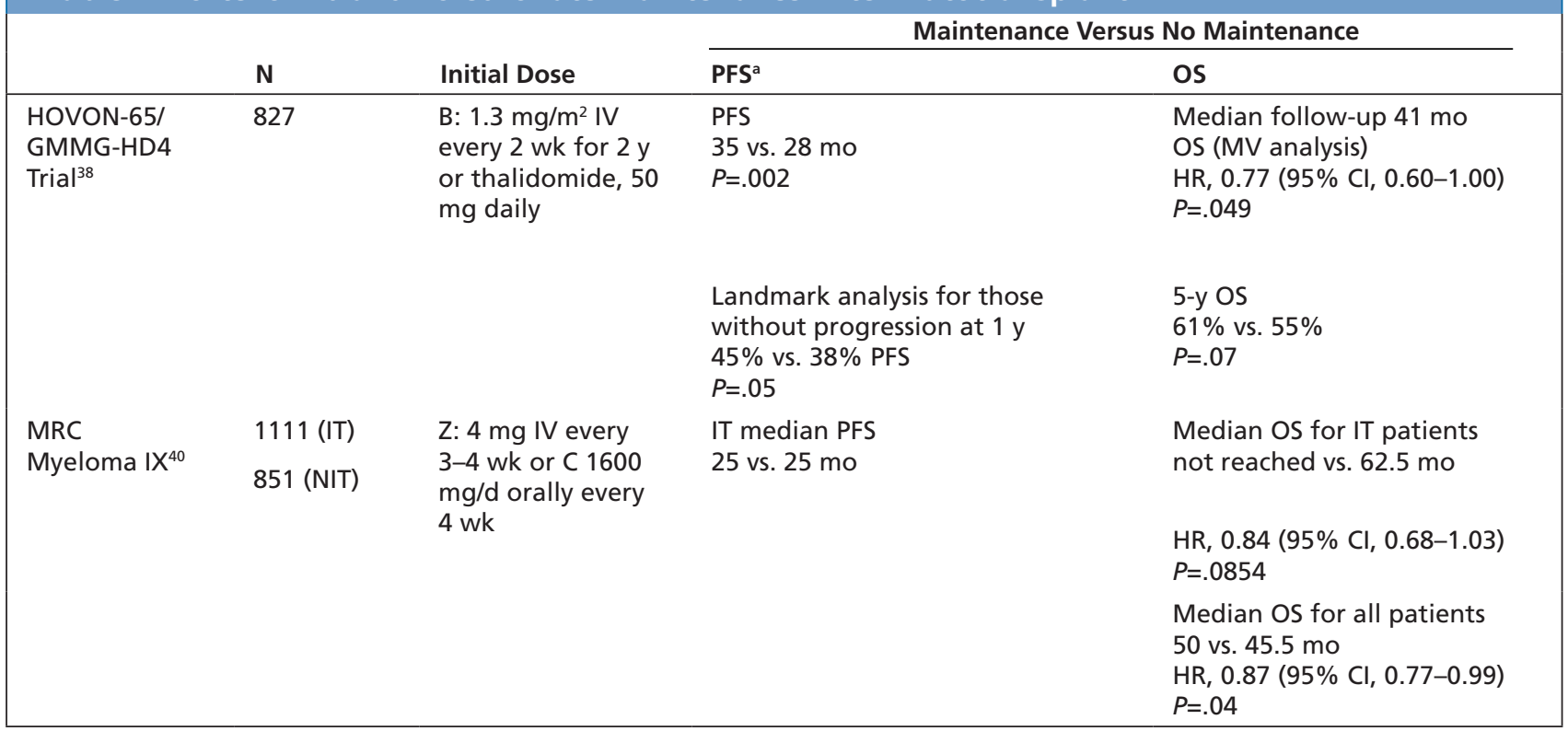

Abbreviations: B bortezomib; C, clodronate; EFS, event-free survival; HR, hazard ratio; IT, intensive therapy; IV, intravenous; NIT, nonintensive therapy; MV, multivariate; OS, overall survival; PFS, progression-free survival; Z, zoledronate.

ancludes deaths, progressions, and second cancers. 
McCarthy

months), a trend was seen toward an improved OS in patients treated with zoledronate (Table 4). Patients in the zoledronate arm did not reach the median OS, whereas it was 62.5 months for patients in the clodronate arm (HR, 0.84; 95\% CI, 0.68-1.03; P=.0854). When the IT and NIT patients were combined in the analysis, a significant improvement in the median OS was seen in the zoledronate arm (50 months) versus the clodronate arm (45.5 months; HR, 0.87; 95\% CI, $0.77-0.99 ; P=.04)$.

\section{Discussion}

Recent studies show that after AHSCT for MM, maintenance therapy with bortezomib for 2 years or with lenalidomide or thalidomide until progression improves PFS and TTP. Zoledronate usually in combination with the previously mentioned agents improves PFS. Bortezomib, lenalidomide, thalidomide, and zoledronate therapy improve OS, although the OS benefit has not been seen in the IFM 05-02 study, and the bortezomib effect may have been from improved induction responses. Bortezomib, lenalidomide, or thalidomide as single agents can be offered as maintenance therapies after induction treatment and AHSCT, with bortezomib and lenalidomide being better tolerated for long-term use. Zoledronate can be offered along with these agents, because its use has been incorporated into these long-term maintenance studies. Thalidomide has been shown to improve PFS and OS in 3 of 5 trials, but its longterm use is limited by neurotoxicity. In the CALGB 100104 and HOVON65/GMMG-HD4 trials, the benefit of maintenance therapy may be optimal when patients experience response to the same agent as part of induction. In both the IFM 05-02 and HOVON65/GMMG-HD4 trials, maintenance therapy with lenalidomide or bortezomib decreased the risk of progression or death in patients with high-risk cytogenetic MM. Thus, either regimen can be considered an acceptable maintenance strategy: bortezomib for 2 years or lenalidomide until progression after AHSCT. The optimal length of maintenance therapy has not been determined. The CALGB 100104 and IFM 05-02 studies were designed to specifically answer the effect of lenalidomide maintenance on PFS with OS as a secondary end point. The IFM 05-02 study did have lenalidomide consolidation for both arms, which leads to a concern regarding lenalido- mide exposure in both arms after transplant. It seems that all patient populations may have benefited from lenalidomide maintenance, but further analysis is necessary to clarify these differences.

MM and monoclonal gammopathy of unknown significance (MGUS) have both been associated with the development of acute myeloid leukemia/ myelodysplastic syndromes. ${ }^{41}$ Patients with MGUS (who would not have received therapy) and, by inference, patients with MM, seem to have an undefined bone marrow defect, predisposing them to the development of myeloid malignancies. These studies have raised questions even as they have answered others. Determining whether specific risk factors exist for SPM and designing optimal treatment strategies to decrease these risks will be important. The HOVON65/GMMG-HD4 trial noted improved OS in the tandem transplant patients. The ongoing BMT-CTN 0702 study was designed to compare single versus tandem transplant versus single transplant followed by consolidation (ClinicalTrials.gov identifier: NCT01109004). All 3 arms are followed by a minimum of 3 years' planned maintenance lenalidomide therapy.

These are exciting times for the treatment of MM. Risk-adapted strategies can be developed for the treatment of patients with MM based on disease status, performance status, and comorbidities. ${ }^{42} \mathrm{New}$ agents, including carfilzomib, pomalidomide, MLN 9708, elotuzumab, and bendamustine, may be considered potential agents for maintenance therapy alone or in combination to maintain long-term disease control. ${ }^{43,44}$ Future studies may examine the use of new agents alone, in combination, or in sequence for maintenance therapy and the optimal length of time of maintenance therapy.

\section{References}

1. Kumar SK, Rajkumar SV, Dispenzieri A, et al. Improved survival in multiple myeloma and the impact of novel therapies. Blood 2008;111:2516-2520.

2. Singhal S, Mehta J, Desikan R, et al. Antitumor activity of thalidomide in refractory multiple myeloma. $\mathrm{N}$ Engl J Med 1999;341:1565-1571.

3. Palumbo A, Bringhen S, Musto P, et al. Oral melphalan, and prednisone chemotherapy plus thalidomide compared with melphalan and prednisone alone in elderly patients with multiple myeloma: randomized controlled trial. Lancet 2006;367:825-831.

4. Richardson PG, Schlossman RL, Weller E, et al. Immunomodulatory drug CC-5013 overcomes drug resistance and is well tolerated in 
patients with relapsed multiple myeloma. Blood 2002;100:30633067.

5. Rajkumar SV, Hayman SR, Lacy MQ, et al. Combination therapy with lenalidomide plus dexamethasone (Rev/Dex) for newly diagnosed myeloma. Blood 2005;106:4050-4053.

6. Dimopoulos M, Spencer A, Attal M, et al. Lenalidomide plus dexamethasone for relapsed or refractory multiple myeloma. $\mathrm{N}$ Engl J Med 2007;357:2123-2132.

7. Weber DM, Chen C, Niesvizky R, et al. Lenalidomide plus dexamethasone for relapsed multiple myeloma in North America. N Engl J Med 2007;357:2133-2142.

8. Richardson PG, Barlogie B, Berenson J, et al. A phase 2 study of bortezomib in relapsed, refractory myeloma. N Engl J Med 2003;348:2609-2617.

9. Richardson PG, Sonneveld P, Schuster MW, et al. Bortezomib or high-dose dexamethasone for relapsed multiple myeloma. $\mathrm{N}$ Engl J Med 2005;352:2487-2498.

10. Harousseau JL, Attal M, Leleu X, et al. Bortezomib plus dexamethasone as induction treatment prior to autologous stem cell transplantation in patients with newly diagnosed multiple myeloma: results of an IFM phase II study. Haematologica 2006;91:1498-1505.

11. San Miguel JF, Schlag R, Khuageva NK, et al. Bortezomib plus melphalan and prednisone for initial treatment of multiple myeloma. N Engl J Med 2008;359:906-917.

12. Cavo M, Tacchetti P, Patriarca F, et al. Bortezomib with thalidomide plus dexamethasone compared with thalidomide plus dexamethasone as induction therapy before, and consolidation therapy after, double autologous stem-cell transplantation in newly diagnosed multiple myeloma: a randomized phase 3 study. Lancet 2010;376:2075-2085.

13. Richardson PG, Weller E, Lonial $S$, et al. Lenalidomide, bortezomib, and dexamethasone combination therapy in patients with newly diagnosed multiple myeloma. Blood 2010;116:679-686.

14. Barlogie B, Attal M, Crowley J, et al. Long-term follow-up of autotransplantation trials for multiple myeloma: update of protocols conducted by the Intergroupe Francophone du Myelome, Southwest Oncology Group, and University of Arkansas for Medical Sciences. J Clin Oncol 2010;28:1209-1214. [Erratum, J Clin Oncol 2010;28:3543.]

15. Alexanian R, Weber D, Giralt S, et al. Impact of complete remission with intensive therapy in patients with responsive multiple myeloma. Bone Marrow Transplant 2001;27:1037-1043.

16. Nadal E, Gine E, Blade J, et al. High-dose therapy/autologous stem cell transplantation in patients with chemosensitive multiple myeloma: predictors of complete remission. Bone Marrow Transplant 2004;33:61-64.

17. Alvares CL, Davies FE, Horton C, et al. Long-term outcomes of previously untreated myeloma patients: responses to induction chemotherapy and high-dose melphalan incorporated within a risk stratification model can help to direct the use of novel treatments. Br J Haematol 2005;129:607-614.

18. Paiva B, Vidriales MB, Cerveró J, et al. GEM (Grupo Español de MM)/PETHEMA (Programa para el Estudio de la Terapéutica en Hemopatías Malignas) Cooperative Study Groups. Multiparameter flow cytometric remission is the most relevant prognostic factor for multiple myeloma patients who undergo autologous stem cell transplantation. Blood 2008;112:4017-4023.

19. Harousseau JL, Avet-Loiseau H, Attal M, et al. Achievement of at least very good partial response is a simple and robust prognostic factor in patients with multiple myeloma treated with high-dose therapy: long-term analysis of the IFM 99-02 and 99-04 trials. J Clin Oncol 2009;27:5720-5726.

20. Southwest Oncology Group Study. Remission maintenance therapy for multiple myeloma. Arch Intern Med 1975;135:147-152.

21. Belch A, Shelley W, Bergsagel D, et al. A randomized trial of maintenance versus no maintenance melphalan and prednisone in responding multiple myeloma patients. Br J Cancer 1988;57:94-99.

22. Fritz E, Ludwig H. Interferon-alpha treatment in multiple myeloma: meta-analysis of 30 randomised trials among 3948 patients. Ann Oncol 2000;11:1427-1436.

23. Berenson JR, Crowley JJ, Grogan TM, et al. Maintenance therapy with alternate day prednisone improves survival in multiple myeloma patients. Blood 2002;99:3163-3168.

24. Attal M, Harousseau JL, Leyvraz S, et al. Maintenance therapy with thalidomide improves survival in patients with multiple myeloma. Blood 2006;108:3289-3294.

25. Barlogie B, Pineda-Roman M, van Rhee F, et al. Thalidomide arm of Total Therapy 2 improves complete remission duration and survival in myeloma patients with metaphase cytogenetic abnormalities. Blood 2008;112:3115-3121.

26. Spencer A, Prince HM, Roberts AW, et al. Consolidation therapy with low dose thalidomide and prednisolone prolongs the survival of multiple myeloma patients undergoing a single autologous stemcell transplantation procedure. J Clin Oncol 2009;27:1788-1793.

27. Lokhorst HM, van der Holt B, Zweegman S, et al. A randomized phase 3 study on the effect of thalidomide combined with adriamycin, dexamethasone, and high-dose melphalan, followed by thalidomide maintenance in patients with multiple myeloma. Blood 2010;115:1113-1120.

28. Morgan GJ, Gregory WM, Davies FE, et al. The role of maintenance thalidomide therapy in multiple myeloma: MRC Myeloma IX results and meta-analysis. Blood 2012;119:7-15.

29. Stewart AK, Trudel S, Bahlis NJ, et al. A randomized phase III trial of thalidomide and prednisone as maintenance therapy following autologous stem cell transplantation (ASCT) in patients with multiple myeloma (MM): the NCIC CTG MY.10 trial [abstract]. Blood 2010;116:Abstract 39a.

30. Krishnan A, Pasquini MC, Logan B, et al. Autologous haemopoietic stem-cell transplantation followed by allogeneic or autologous haemopoietic stem-cell transplantation in patients with multiple myeloma (BMT CTN 0102): a phase 3 biological assignment trial. Lancet Oncol 2011;12:1195-1203.

31. Maiolino A, Hungria VT, Garnica M, et al. Brazilian Multiple Myeloma Study Group (BMMSG/GEMOH). Thalidomide plus dexamethasone as a maintenance therapy after autologous hematopoietic stem cell transplantation improves progression-free survival in multiple myeloma. Am J Hematol 2012;87:948-952.

32. Barlogie B, Pineda-Roman M, van Rhee F, et al. Thalidomide arm of Total Therapy 2 improves complete remission duration and survival in myeloma patients with metaphase cytogenetic abnormalities. Blood 2008;112:3115-3121.

33. Palumbo A, Gay F, Falco P, et al. Bortezomib as induction before autologous transplantation, followed by lenalidomide as consolidation-maintenance in untreated multiple myeloma patients. J Clin Oncol 2010;28:800-807.

34. Palumbo A, Hajek R, Delforge $M$, et al. Continuous lenalidomide treatment for newly diagnosed multiple myeloma. N Engl J Med 2012;366:1759-1769.

35. McCarthy PL, Owzar K, Hofmeister CC, et al. Lenalidomide after stem-cell transplantation for multiple myeloma. N Engl J Med 2012;366:1770-1781. 


\section{McCarthy}

36. Attal M, Lauwers-Cances V, Marit G, et al. Lenalidomide maintenance after stem-cell transplantation for multiple myeloma. N Engl J Med 2012;366:1782-1791.

37. Moreau P, Pylypenko H, Grosicki S, et al. Subcutaneous versus intravenous administration of bortezomib in patients with relapsed multiple myeloma: a randomised, phase 3, non-inferiority study. Lancet Oncol 2011;12:431-440. Erratum in: Lancet Oncol 2011;12:522.

38. Sonneveld P, Schmidt-Wolf IG, van der Holt B, et al. Bortezomib induction and maintenance treatment in patients with newly diagnosed multiple myeloma: results of the randomized phase III HOVON-65/ GMMG-HD4 trial. J Clin Oncol 2012;30:29462955.

39. Neben K, Lokhorst HM, Jauch A, et al. Administration of bortezomib before and after autologous stem cell transplantation improves outcome in multiple myeloma patients with deletion $17 \mathrm{p}$. Blood 2012;119:940-948.

40. Morgan GJ, Davies FE, Gregory WM, et al. First-line treatment with zoledronic acid as compared with clodronic acid in multiple myeloma (MRC Myeloma IX): a randomised controlled trial. Lancet 2010;376:1989-1999.

41. Mailankody S, Pfeiffer RM, Kristinsson SY, et al. Risk of acute myeloid leukemia and myelodysplastic syndromes after multiple myeloma and its precursor disease (MGUS). Blood 2011;118:40864092.

42. Palumbo A, Bringhen $\mathrm{S}$, Ludwig $\mathrm{H}$, et al. Personalized therapy in multiple myeloma according to patient age and vulnerability: a report of the European Myeloma Network (EMN). Blood 2011;118:4519-4529.

43. Mitsiades CS, Hideshima T, Chauhan D, et al. Emerging treatments for multiple myeloma: beyond immunomodulatory drugs and bortezomib. Semin Hematol 2009;46:166-175.

44. Lonial S, Mitsiades CS, Richardson PG. Treatment options for relapsed and refractory multiple myeloma. Clin Cancer Res 2011;17:1264-1277.
DOWNLOAD THE NEW

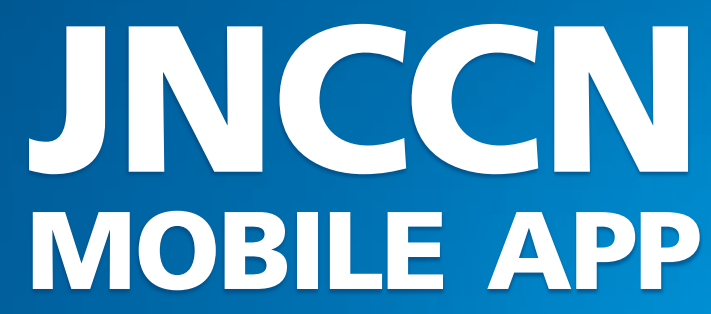

for your iPhone and iPad

\section{Visit us online at JNCCN.org}
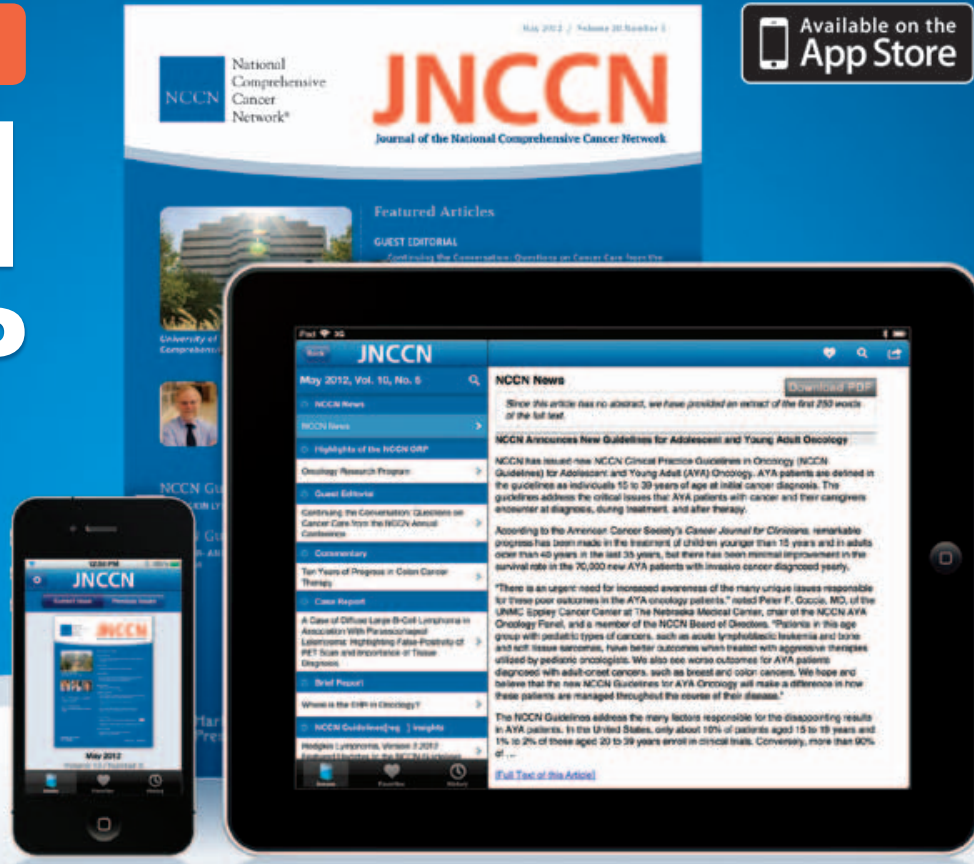

Visit the iTunes store or use your QR code reader to download the JNCCN mobile application.

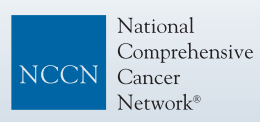

